\title{
Congenital Nervous System Disorder
}

National Cancer Institute

\section{Source}

National Cancer Institute. Congenital Nervous System Disorder. NCI Thesaurus. Code C97172.

An abnormality of the nervous system that is present at birth or detected in the neonatal period. 